\title{
Cleaning Effect of Interlayer Metal on the Joining Surface during Braze Pressure Welding*
}

\author{
Yohei INAGAKI**, Akio SUZUMURA**, \\ Toshi-Taka IKESHOJI** and Takahisa YAMAZAKI**
}

\begin{abstract}
Braze Pressure Welding (BPW) with high frequency induction heating is a newly developed pressure welding technique using interlayer metals for welding the general steel pipes for pipe arrangement in buildings. BPW enables to make joints by solid-state welding in air with relatively small deformation. In this method, the interlayer metal is expected to play the primary role in making high performance joints. It removes contaminations from the joining surface of the base metal and forms fillets at the gaps around the joint. It had been revealed by some experiments and/or numerical analyses in previous research that the BPW joint had higher tensile strength than the brazed joint, and that the fillet can improve the joint strength. In this study, in order to investigate the cleaning effect of interlayer metal more closely, a low carbon steel plate specimen was brazed mainly by Ni-based brazing filler using a tungsten spacer. The microscopy and EPMA analysis on the joints made by various brazing temperatures and durations confirmed that the oxide films on the joining surfaces were removed and discharged from the joining region by the interlayer metal.
\end{abstract}

Key Words: Pressure Welding, Brazing, Carbon Steel Pipe, Interlayer Metal, Oxide Film, Joining Surface

\section{Introduction}

Braze Pressure Welding (BPW) has been supplied as a newly-invented pressure welding technique for joining ordinary steel piping instead of arc welding and bolting commonly used for $\mathrm{it}^{(1)-(3)}$.

Arc welding has such problems as the shortage of skilled welders, the danger of fire breaking by hightemperature welding slag, joint deformation, and the dispersion in joint properties due to welder's skill. For bolt joining, a flange must be shaped at the end of pipe, and requires the space at the installation site for it. A bolted flange pipe connection also needs a sealant inspection and an exchange in a certain span because of its performance degradation.

On the other hand, gas pressure welding needs a high joining stress at high temperatures for increasing the joining area and for breaking up the oxide film on the join-

* Received 25th May, 2005 (No. 05-4121)

** Department of Mechanical and Aerospace Engineering, Graduate School of Science and Engineering, Tokyo Institute of Technology, 2-12-1 O-okayama, Meguro-ku, Tokyo 152-8552, Japan.

E-mail: inagakiy@mep.titech.ac.jp ing surface. When pressure welding is applied to the ordinary piping, the increase of joining area cannot be expected because the diameters of pipes are also expanded though the thickness remains intact. Furthermore, steps or sharp notches are formed around the joint. It causes the stress concentration and the reduction of joining area of the joint.

Brazing is a joining method using an interlayer metal. The base metals are bonded by solidification of the molten interlayer metal between the mating surfaces. The fatigue strength and the fracture toughness of the brazed joint decrease because of the interlayer metal remained at the joining interface.

Liquid phase diffusion welding(4),(5) (Amorphous Diffusion Bonding $\left.{ }^{(6)}\right)$ is also a joining method using an interlayer metal. The bond with this method is formed by isothermal solidification due to the interdiffusion of some elements between liquid phase and base metals while the bonding temperature is maintained. Because the diffusion takes time, the protection of a bonding area from oxidizing is indispensable during bonding. This joining method needs the considerable cost.

BPW is a pressure welding technique using a high 
melting point interlayer metal in air. In the general idea of this technique, the melted interlayer metal is discharged from the brazed region by joining pressure with removing the contaminations such as oxide film on joining surfaces. So the base metals are directly pressure welded under lower joining stress than that in the ordinary pressure welding. The discharged interlayer metal forms fillets at the gaps around the joint. The fillets can be expected to increase the joining area and relax the stress concentration there $^{(7)}$.

In BPW, the interlayer metal is considered to play the important role for getting a high performance joint. The effect of relaxing the stress concentration by the fillet was confirmed in the previous researches with some tensile tests and numerical analyses ${ }^{(8)}$. In order to obtain the evidence on the role of cleaning the joining surface, the joints were produced using the specimens previously oxidized to make oxide film on joining surface, with the nickel-based or iron-based interlayer metal under various joining conditions. Then the joint regions of some joints were investigated by microscopy and electron probe microanalysis (EPMA).

\section{Experimental}

Metal surfaces are generally covered with oxide films. In BPW, it is necessary to remove the oxide film on the joining surface under comparatively lower pressure which has negative effects on pressure welding. In order to investigate the oxide film behavior in the joining region, iron specimens covered with prepared oxide films were brazed with a Ni-based or a Fe-based interlayer metal. The Nibased interlayer metal, whose primary constituent is different from the base metal, was used for examining the oxide film behavior in the brazed region under an optical microscope easily.

\subsection{Materials}

The base metal of a low carbon steel ( 0.15 mass $\%$ C) was obtained in the form of washers with the outside diameter of $24 \mathrm{~mm}$, the inside diameter of $14 \mathrm{~mm}$ and the thickness of $4.5 \mathrm{~mm}$. The joining width of the specimen of $5 \mathrm{~mm}$ is equal to the width of the ordinary carbon steel pipe of SGP150A (JIS). The base metal contains almost the same mass carbon ratio as the ordinary steel pipe used in the previous reports ${ }^{(1)-(3),(8)}$. The joining surface was ground to a 1500 grid finish.

The interlayer metals selected for this investigation were BNi-2 which contains melting point depressants such as boron and silicon, and Fe-based interlayer metal of CR$3 \mathrm{~B}$ which is supplied in the practical BPW process. They were formed into sheet with an organic binder. The chemical composition of $\mathrm{BNi}-2$ and $\mathrm{Cr}-3 \mathrm{~B}$ are given in Tables 1 and 2 .

The spacers of tungsten were supplied in the form of sheet with the thickness of $0.15 \mathrm{~mm}$ or the wire with the diameter of $0.15 \mathrm{~mm}$. The specimens and $\mathrm{W}$ spacers were ultrasonically cleaned in ethanol.

\subsection{Preparation of iron oxide films}

Oxide films were prepared on the steel specimen surfaces through the oxidation treatment in air by high frequency induction heating. The specimen was heated up to $800^{\circ} \mathrm{C}$ in $105 \mathrm{~s}$, held for $2-5 \mathrm{~s}$ and then air-cooled to room temperature. Then $5-10 \mu \mathrm{m}$ thick oxide film was formed on the joining surface. The result of quantitative element analysis of the oxide film is listed in Table 3.

\subsection{Experimental procedure}

The brazing was performed in a vacuum chamber of below $1 \times 10^{-3}$ torr for observing the oxide film and some inclusion's behaviors in the brazed region.

Joining was achieved using the pairs of washer/interlayer and spacer/washer assembly. After arranging the interlayer, the spacers and the specimens, the assembly was mounted on a loading device. It was pressed under $0.75 \mathrm{MPa}$ for axial direction, and was

Table 1 Chemical composition of CR-3B (mass\%)

\begin{tabular}{|c|c|c|c|c|c|}
\hline $\mathrm{Cr}$ & $\mathrm{B}$ & $\mathrm{Si}$ & $\mathrm{C}$ & $\mathrm{Ni}$ & $\mathrm{Cu}$ \\
\hline 13.08 & 3.11 & 1.25 & 0.09 & 0.15 & 0.02 \\
\hline \hline $\mathrm{Mn}$ & $\mathrm{Mo}$ & $\mathrm{Fe}$ & Solidus $\left({ }^{\circ} \mathrm{C}\right)$ & Liquidus $\left({ }^{\circ} \mathrm{C}\right)$ \\
\hline 0.11 & 0.99 & $\mathrm{Bal}$ & 1203 & 1219 \\
\hline
\end{tabular}

Table 2 Chemical composition of BNi-2 (mass\%) (JIS)

\begin{tabular}{|c|c|c|c|c|}
\hline $\mathrm{Cr}$ & $\mathrm{B}$ & $\mathrm{Si}$ & $\mathrm{Fe}$ & $\mathrm{C}$ \\
\hline $6.0-8.0$ & $2.75-3.50$ & $4.0-5.0$ & $2.5-3.5$ & $<0.06$ \\
\hline \hline $\mathrm{P}$ & $\mathrm{Ni}$ & Solidus $\left({ }^{\circ} \mathrm{C}\right)$ & Liquidus $\left({ }^{\circ} \mathrm{C}\right)$ \\
\hline$<0.02$ & $\mathrm{Bal}$ & 970 & 1000 \\
\hline
\end{tabular}

Table 3 Quantitative analysis of the prepared oxide film on specimen (mass\%)

\begin{tabular}{|c|c|c|c|c|c|}
\hline $\mathrm{Cr}$ & $\mathrm{Si}$ & $\mathrm{C}$ & $\mathrm{Ni}$ & $\mathrm{Fe}$ & $\mathrm{O}$ \\
\hline 0.026 & 0.027 & 0.118 & 0.011 & 76.684 & 23.135 \\
\hline
\end{tabular}

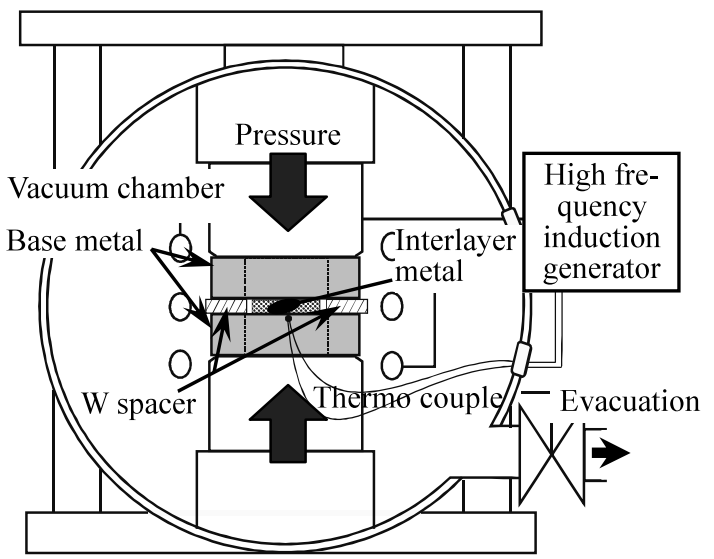

Fig. 1 Schematic diagram of joining apparatus and assembly of specimens 
induction heated. A chromel-alumel thermocouple was spot-welded onto the outside edges of the test specimen for temperature control. The schematic diagram of the joining apparatus and the joining assembly is shown in Fig. 1.

The specimen was heated up to a joining temperature at a ramp rate of about $30^{\circ} \mathrm{C} / \mathrm{s}$. The brazing temperatures were about $30^{\circ} \mathrm{C}$ higher than the liquidus temperature of the brazing fillers used, and BPW temperatures were $1250-1300^{\circ} \mathrm{C}$. The temperature was then held for $0-45 \mathrm{~s}$ before radiative cooling to a room temperature.

After joining, the specimen was characterized by optical microscopy and EPMA.

\section{Result and Discussion}

\subsection{Oxide film in pressure welded joint}

Pressure welding commonly requires high joining
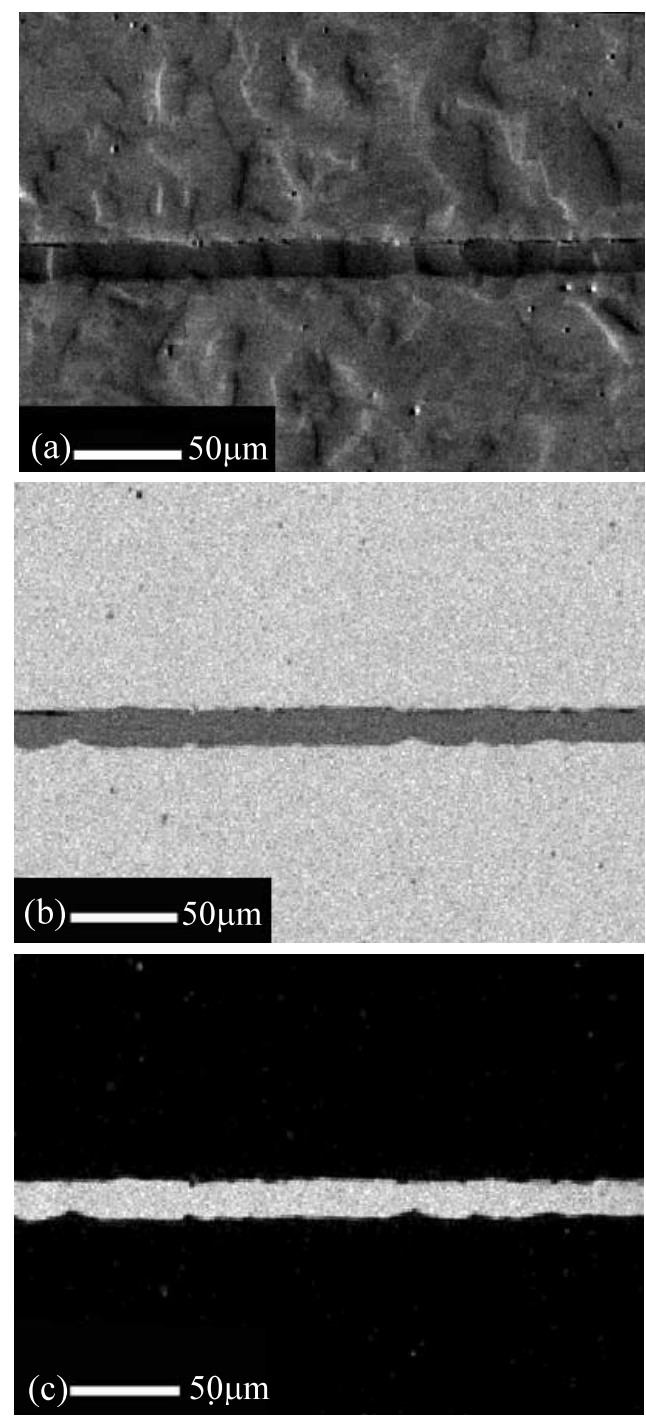

Fig. 2 Oxide film in pressure welded joint (a): SEM image of vertical section of the joint, EPMA map analysis of (b): $\mathrm{Fe},(\mathrm{c})$ : $\mathrm{O}$ at the same area as (a) stress for breaking the oxide films on joining surfaces. A scanning electron micrograph and the map of $\mathrm{O}$ and Fe of a pressure-welded joint made under the pressure of 1.5 $\mathrm{MPa}$ at $1100^{\circ} \mathrm{C}$ for $10 \mathrm{~s}$ using the oxidized base metals are shown in Fig. 2. It is confirmed that about $20 \mu \mathrm{m}$-thick contamination layer constituted with oxygen lies along the joint surface. The result of quantitative element analysis of the layer is listed in Table 4.

These results reveal that the layer was constituted with the oxide of iron preformed on the base metal before joining. They also show that the oxide film obstructs the direct contact of base metals in the pressure-welded joint under the relatively low joining stress, and that oxide films cannot be broken only by heating in vacuum.

\subsection{Removing process of oxide films on joining surfaces}

Figure 3 shows the brazed joint produced at $1030{ }^{\circ} \mathrm{C}$ for $1 \mathrm{~s}$ using the BNi-2. The joint has no inclusion on the interface. In contrast, the micrographs of the joints made at the same temperature as the joint in Fig. 3 with the oxidized base metals are shown in Fig. 4. The specimens were heated for $5 \mathrm{~s}$ (a), $8 \mathrm{~s}$ (b) and $20 \mathrm{~s}$ (c), respectively, until they were cooled down below the solidus of $\mathrm{BNi}-2$, after heated up above the liquidus in joining process.

The joints with oxidized base metals have contaminations in the brazed region. The contamination layer closely overlaps the joining surface of base metal in (a). It becomes thinner and detached from the interface in (b), then their forms are transformed into round shape in (c). The inclusions were considered to be produced from the prepared iron oxide films on the base metal derived from the comparison with Fig. 3. The molten interlayer metal would dissolve the oxide film and the base metal through

Table 4 Quantitative analysis of the contamination layer in the pressure-welded joint (mass\%)

\begin{tabular}{|c|c|c|c|c|c|}
\hline $\mathrm{Cr}$ & $\mathrm{Si}$ & $\mathrm{C}$ & $\mathrm{Ni}$ & $\mathrm{Fe}$ & $\mathrm{O}$ \\
\hline 0.038 & 0.099 & 0.297 & 0.011 & 81.905 & 17.285 \\
\hline
\end{tabular}

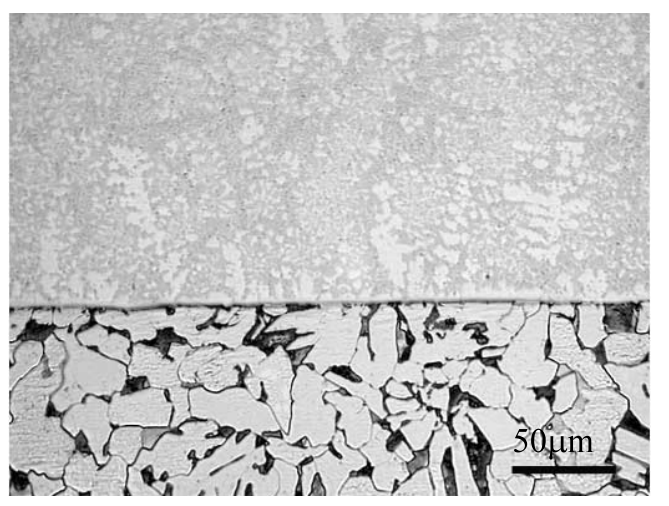

Fig. 3 Interface of brazed joint made at $1030^{\circ} \mathrm{C}$ for $1 \mathrm{~s}$ using the polished clean specimen 

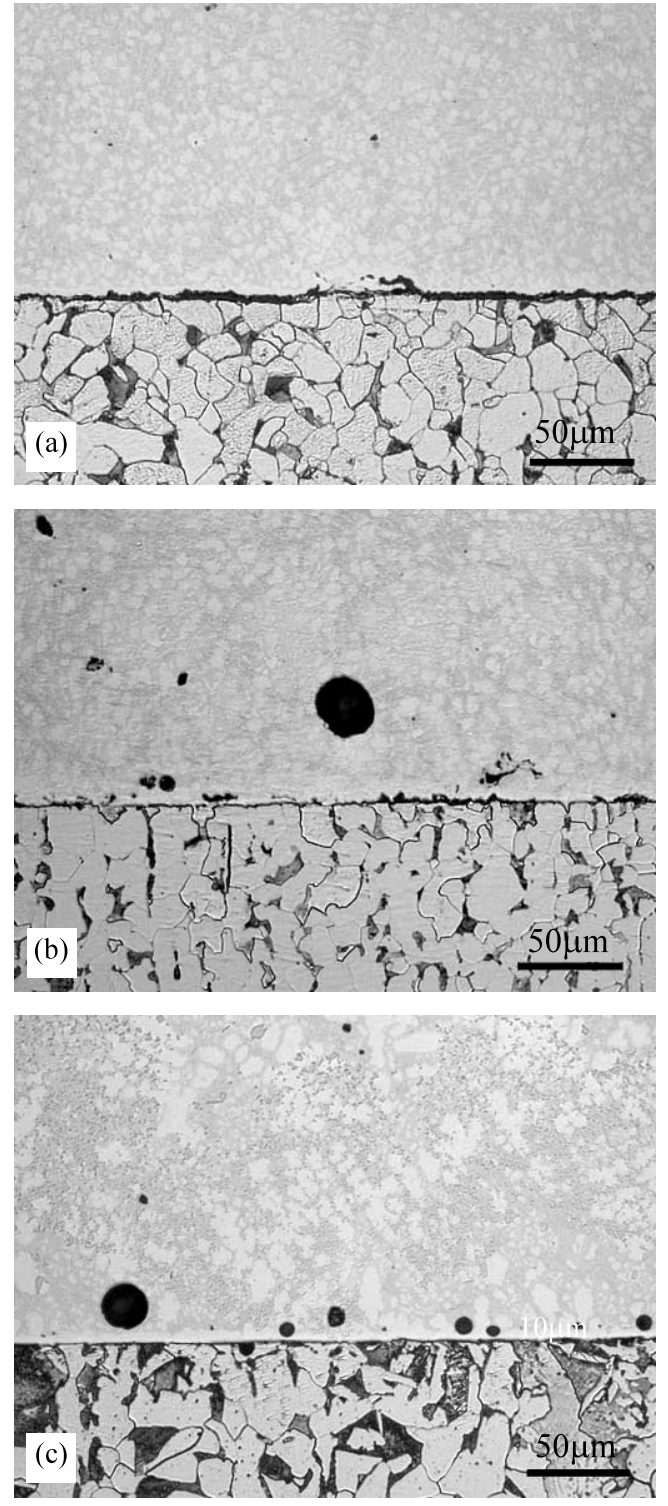

Fig. 4 Oxide film behavior in the bonded region made at $1030^{\circ} \mathrm{C}$ for $1 \mathrm{~s}(\mathrm{a}), 2 \mathrm{~s}(\mathrm{~b}), 3 \mathrm{~s}(\mathrm{c})$

the crack in the oxide film, where the crack could be made by the difference in the thermal expansion between the base metal and the oxide film. Then the oxide film was removed from the base metal, and the molten interlayer metal could directly contact with the base metal.

Figure 5 shows a void formed in the brazed region of the joint made at $1170^{\circ} \mathrm{C}$ for $40 \mathrm{~s}$ with $\mathrm{W}$ wires as spacer. The result of quantitative analysis on the internal surface of the hole in the given circular area in Fig. 5 is indicated in Table 5. It reveals that the surface would be composed of oxygen, carbon and the interlayer metal elements.

Figure 6 shows the interlayer metal discharged from the brazed region. The joint is the same as shown in Fig. 5 . There are some inclusions around the edge of joint. This suggests that the inclusions produced in the welding area are ejected from the brazed region with the molten inter-

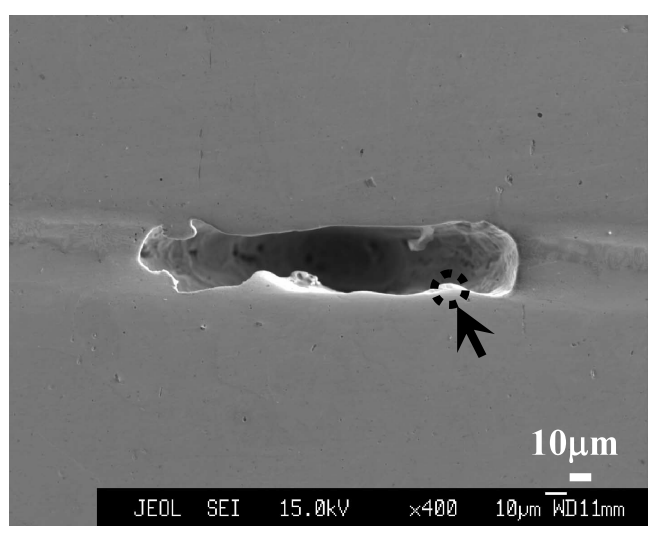

Fig. 5 SEM micrograph of the void formed in the joint area made at $1170^{\circ} \mathrm{C}$ for $40 \mathrm{~s}$ with $\mathrm{W}$ spacer

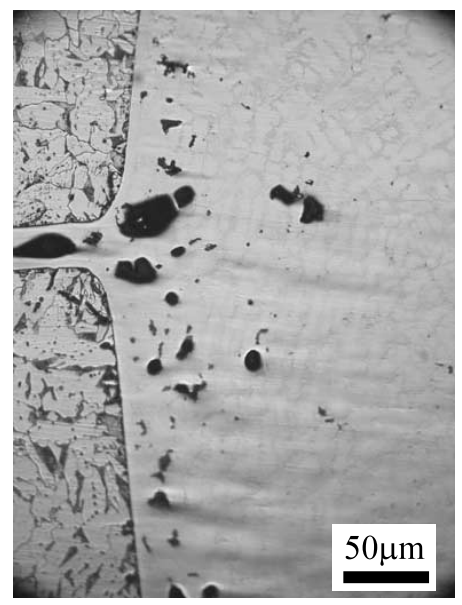

Fig. 6 Micrograph of the contaminations ejected from the joint region. The joint is the same as shown in Fig. 5.

Table 5 Quantitative analysis on the internal surface of the void shown in Fig. 5 (mass\%)

\begin{tabular}{|c|c|c|c|}
\hline $\mathrm{Cr}$ & $\mathrm{B}$ & $\mathrm{Si}$ & $\mathrm{C}$ \\
\hline 4.380 & 1.637 & 3.106 & 2.738 \\
\hline \hline $\mathrm{O}$ & $\mathrm{Ni}$ & $\mathrm{Fe}$ & Total \\
\hline 6.281 & 32.24 & 49.61 & 100 \\
\hline
\end{tabular}

Table 6 Quantitative analysis on the solid inclusion shown in Fig. 7 (mass\%)

\begin{tabular}{|c|c|c|c|}
\hline $\mathrm{Cr}$ & $\mathrm{B}$ & $\mathrm{Si}$ & $\mathrm{C}$ \\
\hline 6.580 & 0.500 & 0.404 & 1.744 \\
\hline $\mathrm{O}$ & $\mathrm{Ni}$ & $\mathrm{Fe}$ & Total \\
\hline 5.102 & 48.763 & 35.664 & $\cong 100$ \\
\hline
\end{tabular}

layer metal.

The element distribution on the solid inclusion formed in the joint region was analyzed by EPMA. The map of $\mathrm{O}, \mathrm{C}$ and $\mathrm{Fe}$ are indicated in Fig. 7. The result of quantitative element analysis on the inclusion in the given circular area is shown in Table 6. Figure 7 reveals that the inclusion surface involves oxygen and carbon. The quantitative analysis suggests that the inclusions could be 

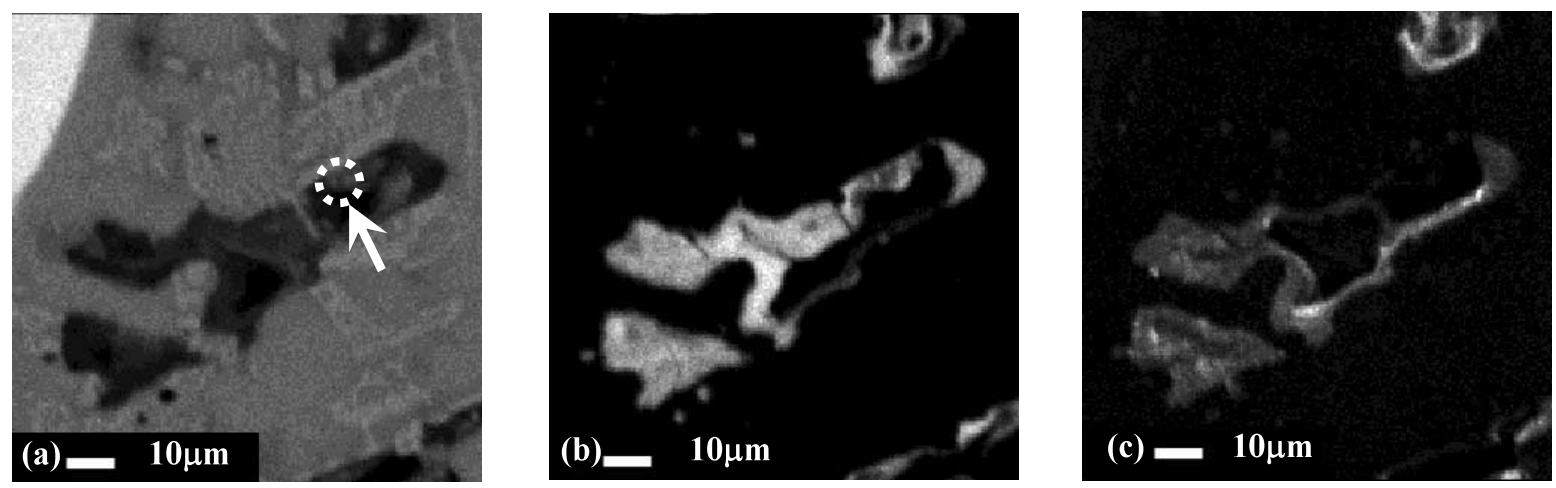

Fig. 7 Map of (a): Fe, (b): $\mathrm{O}$, and (c): $\mathrm{C}$ on the solid inclusion. The joint is the same as showing in Figs. 5 and 6.

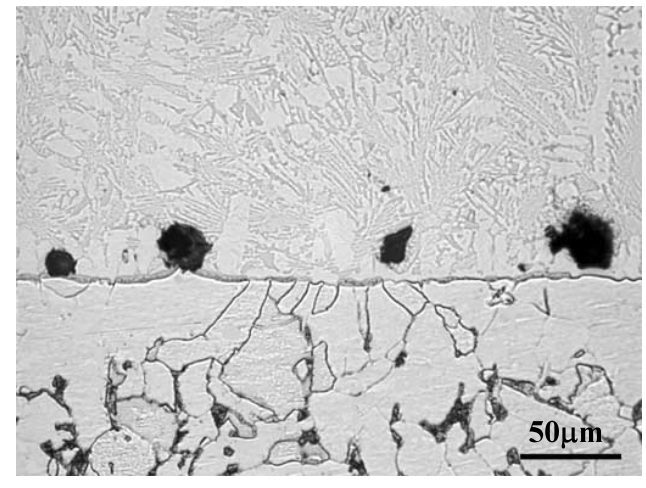

Fig. 8 Microstructures of brazed joint interface made at $1250^{\circ} \mathrm{C}$ for $1 \mathrm{~s}$ using Fe-based brazing filler, CR-3B
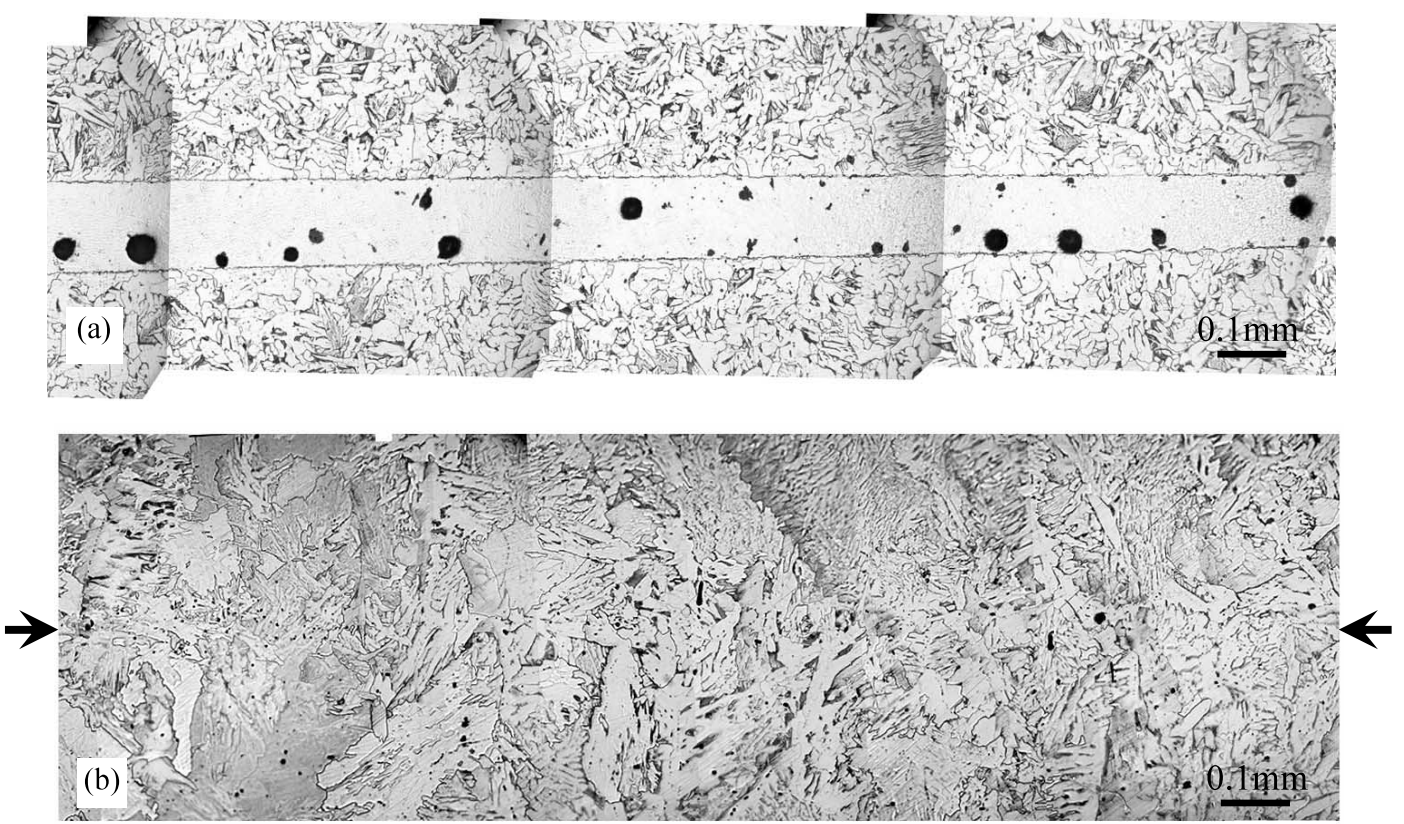

Fig. 9 Microstructures of brazed joints made at $1300^{\circ} \mathrm{C}$ for $2 \mathrm{~s}$ (a) and $7 \mathrm{~s}$ (b) with $\mathrm{Cr}-3 \mathrm{~B}$

formed from the prepared oxide films and/or the organic binder used for interlayer metal forming.

These factors reveal that the molten interlayer metal can make oxide films detach from the joining surface and pick up the film in itself. The molten interlayer metal in- volving the contaminations is discharged from the joining region. There are voids and solid contaminations formed of the prepared oxide films on the joining surfaces and/or the organic binder in the brazed joint. The void could be produced from some of these solid contaminations by their 


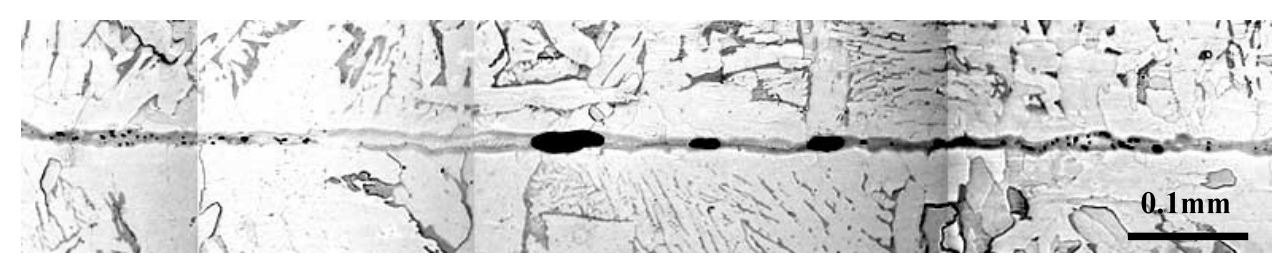

Fig. 10 BPW joint interface using oxidized specimen having about $6 \mu \mathrm{m}$-thick oxide film. The joint was made at $1250^{\circ} \mathrm{C}$ for $10 \mathrm{~s}$ under $7 \mathrm{MPa}$, where only some voids and inclusions are observed, but not oxide film.

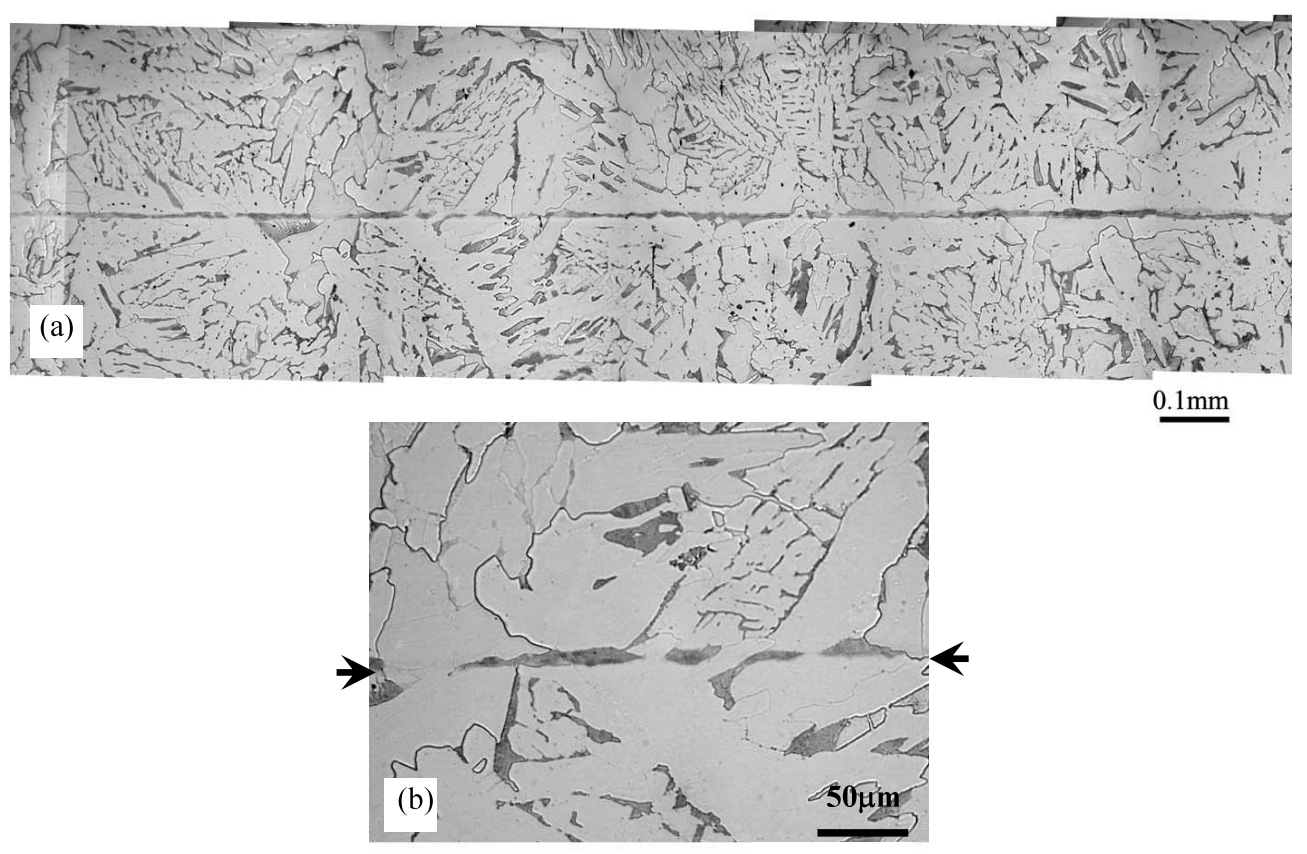

Fig. 11 Microstructure of the BPW joint welded at $1250^{\circ} \mathrm{C}$ for $10 \mathrm{~s}$ under $7 \mathrm{MPa}$ in lowmagnification micrograph; (a) and high-magnification micrograph; (b)

gasification.

\subsection{Joint with Fe-based interlayer metal}

Figure 8 shows the micrograph of the brazed joint using Fe-based brazing filler of CR3B at $1250^{\circ} \mathrm{C}$ for $1 \mathrm{~s}$. The interface has been cleared, and some inclusions along the base metal surface are observed.

In the practical BPW for ordinary steel pipe, the joining temperature of $1300^{\circ} \mathrm{C}$ is adopted, then the joints made at $1300{ }^{\circ} \mathrm{C}$ for $2 \mathrm{~s}$ and $7 \mathrm{~s}$ are shown in Fig. 9(a) and (b), respectively. There are circular inclusions transformed from the solid inclusions in (a). There are pearlite and bainite-like structures around the joint region, where no inclusion can be observed in (b). It would be suggested that interdiffusion has been occurred between the base metal and the interlayer metal, and then austenite of the base metal transforms to pearlite and bainite-like structure throughout the joint region during cooling.

Figure 10 shows the micrograph of BPW joint using the oxidized base metals having about $20 \mu \mathrm{m}$ thick oxide film as shown in Fig. 2. The specimens are pressed under $8 \mathrm{MPa}$. The joining temperature is $1250^{\circ} \mathrm{C}$ and held for $10 \mathrm{~s}$. It is confirmed that the molten interlayer metal was removed and discharged the most oxide films from the joining surfaces, and then the base metals were pressurewelded to each other on the cleared surfaces without contaminations.

Figure 11 shows the BPW joint using non-oxidized specimens, which are held for $30 \mathrm{~s}$ at $1250^{\circ} \mathrm{C}$. The specimens are welded without any contaminations at the interface, where the interlayer metal has been discharged from the joint region, then the base metals would be directly pressure-welded to each other. These results reveal that the interlayer metal used in BPW process dissolves and discharges the contaminations like oxide films, which makes it easy to pressure-weld the base materials directly to each other.

\section{Conclusions}

The cleaning effect of the interlayer metal for BPW on the joining surfaces had been confirmed by the experiment using the oxidized joining surfaces of specimens in this study.

Molten interlayer metal dissolves the oxide film on 
the joining surfaces and makes it detached from there. The removed oxide films and the binder for the interlayer metal sheet forming could produce solid inclusions and voids in the joint region. The molten interlayer metal ejects these contaminations from joining interface.

The base metals with cleared joining surfaces can be produced with the sound pressure-welded joint without contaminations at the joining interface.

\section{References}

( 1 ) Suzumura, A., Inagaki, Y., Ikeshoji, T. and Ueno, Y., Braze Pressure Welding (BPW)—A New Method for High Quality Pressure Welding, JSME Int. J., Ser. A, Vol.46, No.3 (2003), pp.208-212.

(2) Suzumura, A., Ikeshoji, T., Inagaki, Y. and Ueno, Y., Braze Pressure Welding (BPW)—A New Method for High Quality Pressure Welding_, JSME/ASME International Conference on Materials and Processing 2002-The 10th JSME Materials and Processing, Vol.2 (2002), pp.23-28.

( 3 ) Suzumura, A., Ikeshoji, T., Mochida, T. and Ueno, Y., The Relationship between Bonding Conditions and
Strength of Pressure-Welding Steel Pipe Joints Using Brazing Filler, (in Japanese), The 8th Materials and Processing Conference (M\&P2000), (2000), pp.325326.

( 4 ) Duvall, D.S., Owczarski, W.A. and Paulonis, D.F., TLP* Bonding: A New Method for Joining Heat Resistant Alloys, Welding Journal, Vol.53, No.4 (1974), pp.203-214.

( 5 ) Suzumura, A., Onzawa, T. and Tamura, H., Effects of Using Amorphous Interlayer on Liquid Phase Diffusion Welding Process, Quarterly Journal of the Japan Welding Society, (in Japanese), Vol.3, No.2 (1985), pp.85-92.

( 6 ) Yasuto, F., Kashimoto, F., Komizo, Y., Kishi, N. and Kitano, K., Diffusion Bonding System, Sumitomo Metals, (in Japanese), Vol.43, No.7 (1991), pp.171-177.

( 7 ) Nishida, M., Stress Concentration, (1991), pp.642647, Morikita Shuppan Co., Ltd.

( 8 ) Inagaki, Y., Suzumura, A. and Ikeshoji, T., The Effects of Fillet Formation on the Strength of Braze Pressure Welded Joint with High Frequency Induction Heating, DVS, Brazing, High Temperature Brazing and Diffusion Welding, (2004), pp.175-180. 